\title{
Business Analysis and Future Development of an Electric Vehicle Company--Tesla
}

\author{
Xuan Shao ${ }^{1, *, a, \uparrow}$, Qin Wang ${ }^{2, *, b, \dagger}$, Haoyi Yang ${ }^{3,{ }^{3}, \mathrm{c}, \uparrow}$ \\ ${ }^{1}$ School of Environment and Architecture, University of Shanghai for Science and Technology, 200093, Shanghai, \\ China \\ ${ }^{2}$ College of Science, Old Dominion University, 23529, Norfolk, Virginia, USA \\ ${ }^{3}$ Academy of Television Arts, Zhejiang Communication University, 310018, Hangzhou, China

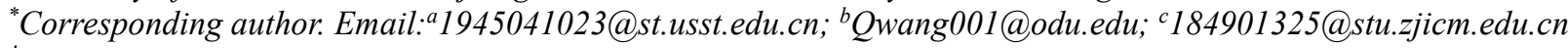 \\ These authors contributed equally.
}

\begin{abstract}
The boom in electric vehicles in recent years has caught the attention of many companies that are investing or will be investing in the industry due to the increasing demand for electric cars. Tesla as a leader of the electric vehicles (EVs) industry, its development is of vital significance for referential value. Previous research on electric vehicle acceptance and behavioral intention of purchase is comprehensive, which could enable the EVs industry to understand consumer psychology. However, there is little analysis of the business strategy and future development of specific companies. When it comes to sustainability, almost every company has a path that is best suited to. This paper presents a comprehensive review of the historical background of Tesla, followed by in-depth states on its current strategy and future analysis. Given recommendations on its future development, Tesla could engage more in other different industries to increase the source of revenue and invest more into the development of autonomous public transportation, such as electric car-sharing services (ECS). These will help Tesla move steadily into the next stage.
\end{abstract}

Keywords: Tesla, ECS, Industry development, Electric vehicle.

\section{INTRODUCTION}

Tesla is now a world-famous manufacturer and distributor of electric vehicles. The technology content, appearance design, product quality, and popularity of its products have exceeded those of most countries in the world. Today, Tesla has been constantly refreshing people's understanding of electric vehicles, promoting and leading the development of the electric vehicle industry in the whole society. From these points of view, Tesla can be called a company that changes the world on its own.

Tesla's current innovation and development direction mostly focus on the research of business models and the promotion of the development of electric vehicles. From the day of its birth, Tesla has been an anticipated and admirable company. Tesla's brand has always been pasted together with labels such as environmental protection and high technology, walking in the forefront of the world. This really attracted a large number of consumers in the early stage of brand development and achieved the marketing effect of less than intention. With the blessing of this aura, Tesla, after stabilizing its domestic market, has changed to expand its foreign market. In this article, we will talk about Tesla's company background, the company's future development, and the obstacles it may encounter.

The global car demand is huge in the future. In 2030, the global car number will be increased from 1.3 billion to 2 billion, which also includes growth in demand for electric vehicles as lithium-ion batteries become more common [1]. Battery electric vehicles (BEVs) ownership is increasing in wealth, income, and education [2]. The analysis results of the behavioral intention of Malaysian consumers to purchase electric vehicles show that there is a significant positive correlation between functional value, emotional value, and consumers' attitudes towards electric vehicles. In contrast, infrastructure readiness does not regulate the relationship between consumers' attitudes towards electric vehicles and purchase intention [3]. Several European governments have launched plans to roll out electric vehicles to reverse rising carbon dioxide emissions from the European Union's transport sector [4]. 
An investigation of people's choice of electric cars in Canada found that people most frequently associate BEVs (battery electric vehicles) with Tesla, Toyota, and Chevrolet. More than two-thirds of respondents are familiar with Tesla and 40 percent believe that Tesla represents the future of BEVs [5]. Tesla has proven to be competitive in markets such as the United States where other electric car makers exist. Tesla's three series of Model X, Model S, and Model 3 all made the top four in 2018's ranking of the best-selling electric cars [6]. Tesla ranks among the best in the world in a better innovation environment, stands at the forefront of the technological innovation environment, rapidly subversive innovation, first leading the high-end demand, and then extending to the low-end terminal is Tesla's business model [7]. A performance track describing Tesla's entry into the automotive market was constructed and it proved that Tesla did not follow the disruptive innovation strategy. Instead, Tesla's commercialization strategy is explained by architectural innovation and the advantages of attackers [8]. In addition to focusing on providing a unique architecture for battery issues and customers' range anxiety, Tesla is also adapting its organization and strategy to the needs of other key stakeholders in the larger EV ecosystem by gradually mastering effective systems integration [9]. However, despite Tesla's strong business strategy, issues such as insufficient charging infrastructure, difficulty in mass production, and competition with the existing auto industry remain [10]. Thus, it is crucial to study the future development of Tesla.

To understand whether Tesla is providing the transportation of the future through its electric cars, we used the survey methodology. This method involved looking at Tesla's past 4 years' financial performance and projecting the company's future performance. The survey methodology also involved looking at the company's key competitors such as legacy manufacturers including General Motors, Volkswagen, and Ford among other new entrants such as XPeng and NIO companies which are China-based companies. The purpose of using the survey methodology is to understand how Tesla through its increased focus on electric cars manufacturing will become the solution to future transportation bringing growth to this company.

After conducting a survey analysis which entailed looking at the company's previous performance and making a projection of Tesla's future growth, we discovered that Tesla has in the last four years been registering a loss when it comes to income. Despite Tesla's increased focus on electric cars, the fact is that they are continuing to register significant income losses. However, there is a positive trend. This is because since the 2017 financial year, the company net income loss has been reducing and the amount of revenue is increasing. From our survey, this is being attributed to the fact that many consumers have started to gain more confidence in electric cars and the world has become more environmentally conscious. From our survey, we also discovered that Tesla's future is threatened by the fact that more competitors are considering the manufacturing of electric cars, and this includes general motors. Such competition will threaten the company's future growth. Despite the threat facing Tesla, the fact is that the company has the potential to grow in the future since it has significantly invested in electric car manufacturing and research.

The paper starts by looking at Tesla's revenue and profit from the 2017 to 2020 financial year. The paper also looks at the company's share price examining how this has grown significantly especially from 2018. The paper also provides the research method and research outcome utilized in gathering the necessary data. The paper ends by looking at the competitors who are the major threat to Tesla's future growth.

\section{FIRM DESCRIPTION}

Tesla is a new electric vehicle company in the United States, dedicated to the research, development, and sales of electric vehicles and batteries. Tesla was founded on July 1, 2003, by a group of engineers who wanted to prove that electric vehicles are better, faster, and more fun to drive than fuel vehicles. The original founders were Martin Eberhard and Mark Tapenning who opened their headquarters in Palo Alto California. Elon Musk soon joined the company in 2004 with an initial investment of 30 million dollars. By 2008 Elon Musk had taken over Tesla as the CEO.

Tesla has a unique operation model of integrating the industrial chain: The company has a history of using superior products developed by other enterprises for use Tesla vehicles (For example, Panasonic batteries). Tesla has continuously reduced manufacturing costs and improve the performance of their products. Tesla has developed core technologies with independent property rights. This includes the research and development of autopilot chips which Tesla has mastered core technology for. Finally, Tesla has filed many open technology patents which aim to promote more auto parts or vehicle manufacturers to join Tesla's scientific research team and share the cost of scientific research.

Tesla has built a set of intelligent service systems with customer-centered sales and after-sales integration through the Internet, providing customers with specialized online or offline services: Online services include a virtual service center that can carry out remote diagnosis and even maintenance when the vehicle fails. Offline services include offering a spare vehicle to help Tesla owners complete their journey should any issues arise with their Tesla.

According to Tesla's financing tables over the years (Table 1). We can see that Tesla's financing target has 
changed from individuals and small companies to large multinational enterprises, and the amount of financing is gradually expanding. The financing time from 2004 to 2009 is stable, once a year. The objects of financing are mostly individuals or small companies. But in 2010, due to financial and technical problems, they raised funds twice a year. They are strategic financing from Panasonic and equity investment from the development bank. After seven years of development, Tesla developed, produced, and launched a new batch of models to further open the market. The company decided to make further financing. This time, the financing object has become a large multinational enterprise due to the change of capital needs and financing purposes. The amount of financing also increased sharply. Such a large amount of capital investment has greatly promoted Tesla's product development and marketing.

Table 1. Financing overview of Tesla.

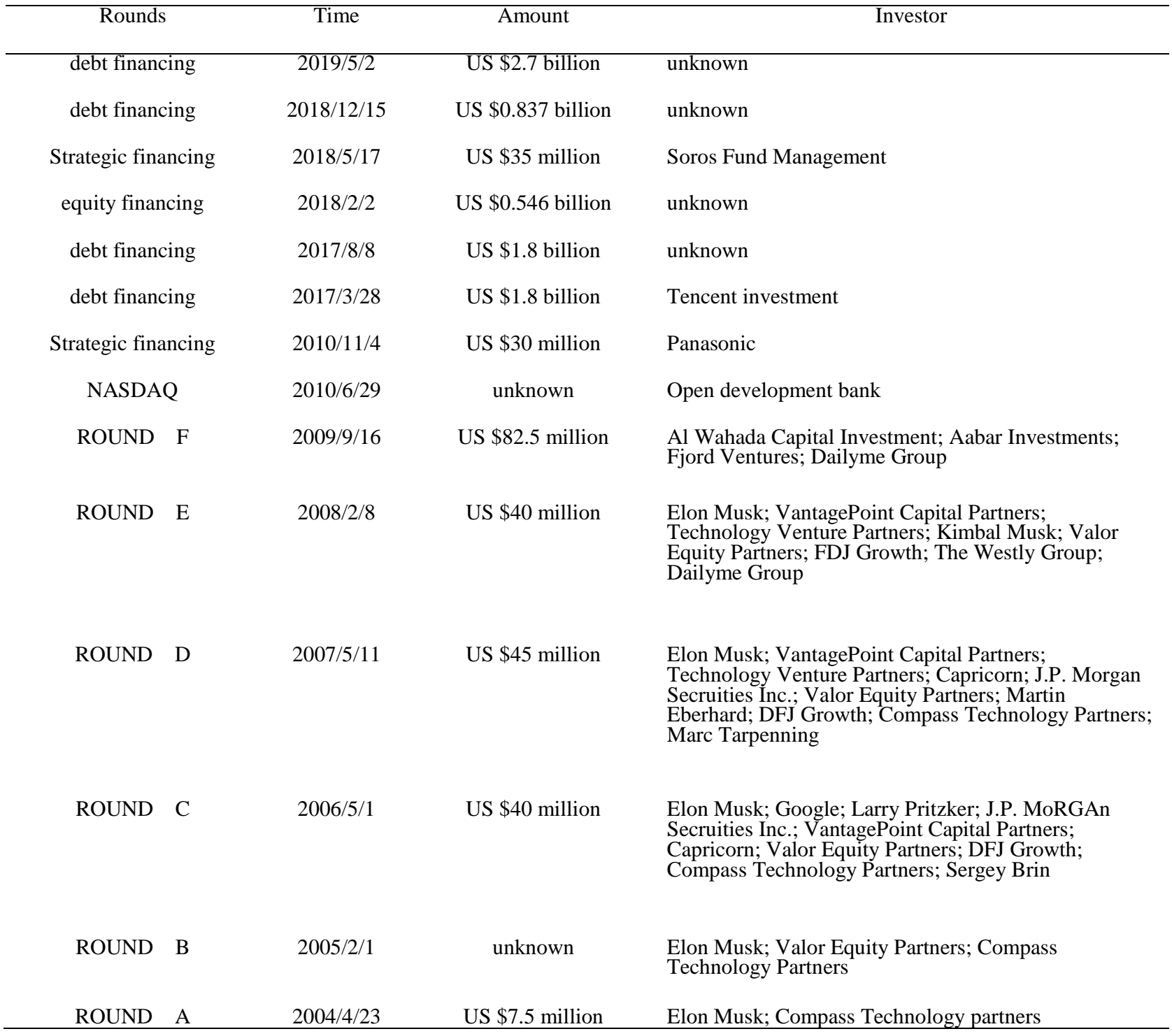

\section{CURRENT STRATEGY}

Tesla's business strategy has a positive reference role for new industry entrants and industry investors. Understanding the current strategy of a target company is one of the important sources for analyzing its success factors or lessons from its failure. Tesla's current strategy will be discussed from three perspectives: the company's zero advertising budget, vertically integrated services, and market segmentation.

\subsection{Zero advertising budget}

Tesla's zero-budget advertising spending is no secret to the automobile industry. 
According to a report from BrandTotal in 2019, Table 2 shows that eight main competitors of tesla in the automobile industry such as Toyota and Honda maintained the basal expenditure on advertising upon four major social media platforms: Facebook, YouTube, Instagram, and Twitter. For instance, in contrast to Audi, which put $32 \%$ of its social budget on Facebook and 54\% on YouTube, Tesla still didn't spend a dime.

However, despite the lack of advertising investment, Tesla has been highly engaged with the media. The company's iconic CEO, Elon Musk with nearly 60 million followers on Twitter is now keeping frequent interaction with users on those social platforms. Capitalizing well on a huge fan base, in March 2017, Musk held a competition for fan-made ads online and then picked out the best ones for free online commercial use, which has allowed Tesla the reduction of high costs like the traditional advertising as well as the establishment of brand awareness and uniqueness.

Table 2. Auto brands paid media mix.

\begin{tabular}{ccccc}
\hline Brands & Facebook & YouTube & Instagram & Twitter \\
\hline Toyota & $62 \%$ & $18 \%$ & $2 \%$ & $2 \%$ \\
Audi & $32 \%$ & $54 \%$ & $13 \%$ & $1 \%$ \\
BMW & $46 \%$ & $2 \%$ & $32 \%$ & $20 \%$ \\
Ford & $55 \%$ & $39 \%$ & $6 \%$ & $<1 \%$ \\
Honda & $38 \%$ & $33 \%$ & $27 \%$ & $2 \%$ \\
Infiniti & $52 \%$ & $7 \%$ & $40 \%$ & $<1 \%$ \\
Cadillac & $34 \%$ & $40 \%$ & $18 \%$ & $8 \%$ \\
Porsche & $14 \%$ & $47 \%$ & $39 \%$ & $<1 \%$ \\
Tesla & $0 \%$ & $0 \%$ & $0 \%$ & $0 \%$ \\
\hline
\end{tabular}

\subsection{Vertically integrated service}

Tesla is moving toward a vertically integrated service, committed to creating an end-to-end service model from the company itself to its customers. Without intermediaries, the Tesla electric cars as the products of the company will become a dominant bond to establish the connection

Aiming at the reach to customers, the company started from the energy. In 2016, Elon Musk facilitated the merging of Tesla and SolarCity, which significantly expanded the client channel from a solar perspective. Meanwhile, the company is looking at ways to make its accessories such as batteries for electric drives. In February 2020, the "Roadrunner" power battery production plan has been launched. Tesla now has signed an order for battery-making equipment from South Korea's Hanwha Group to produce its power batteries.

The integrated service would allow the company to build competitive differentiation. In the five forces analysis (Figure 1), the bargaining power of suppliers will be mitigated as Tesla increases investment in selfdeveloped accessories. Moreover, to a certain extent, the uniqueness of products and services is more likely to lead to customers' inclination about the brand. Tesla's distinctive brand packaging helps to achieve it, thus reducing the bargaining power of buyers and lowering down the threat of substitute products. At the same time, the barriers to entry for new entrants are intensively connected to the development of electric power. With high technical requirements of electric energy, Chances are that the newly developing domain will not be confronted with the onslaught of new car brands. However, the transformation to the electric energy of existing traditional automobile production companies will become a greater threat to Tesla.

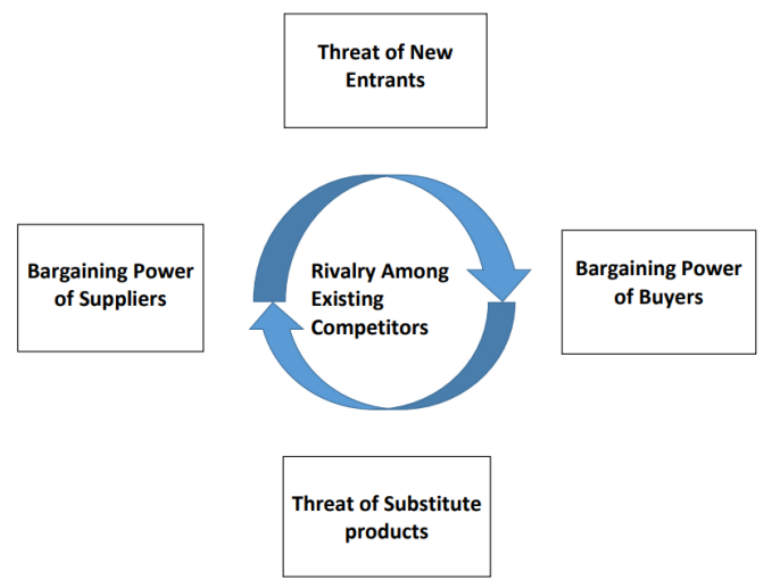

Figure.1. Five forces analysis. 


\subsection{Market segmentation}

Four series of Tesla cars, namely the Model 3, the Model Y, the Model S, and the Model X have shown the company's systematic division. Table 3 shows that the effective price of Model 3 fluctuates between $\$ 41,190$ and $\$ 58,190$ while the highest effective price of Model S can go up to $\$ 131,190$, which indicates the variance of transactions of different models. Tesla capitalizes on a variety of models with different prices to divide the market into high-end and low-end segments. Model S and Model X are now faced with the high-end coupe and SUV market and the other two models are dedicated to the lower end. Hence, the overall consumer grade is segmented into two markets with different target products of the company, which to a certain degree are conducive to the formation of economies of scope and reductions inelastic demands for cars as well.

Table 3. Tesla prices in 2021.

\begin{tabular}{lcccc}
\hline \multicolumn{1}{c}{ Model } & Basic Price & Dest.Charge & Tax Credit & Effective Price \\
\hline 2021 Tesla Model 3 Standard Range Plus & $\$ 39,990$ & $\$ 1,200$ & N/A & $\$ 41,190$ \\
2021 Tesla Model 3 Long Range AWD & $\$ 48,990$ & $\$ 1,200$ & N/A & $\$ 50,190$ \\
2021 Tesla Model 3 Perf.LR AWD 20" & $\$ 56,990$ & $\$ 1,200$ & N/A & $\$ 58,190$ \\
2021 Tesla Model S Long Range (AWD) 19" & $\$ 79,990$ & $\$ 1,200$ & N/A & $\$ 81,190$ \\
2021 Tesla Model S Plaid 19" & $\$ 129,990$ & $\$ 1,200$ & N/A & $\$ 131,190$ \\
2021 Tesla Model X Long Range (AWD) 20" & $\$ 89,990$ & $\$ 1,200$ & N/A & $\$ 121,190$ \\
2021 Tesla Model X Plaid 20" & $\$ 119,990$ & $\$ 1,200$ & N/A & $\$ 54,190$ \\
2021 Tesla Model Y Long range AWD 19" & $\$ 52,990$ & $\$ 1,200$ & N/A & $\$ 62,190$ \\
2021 Tesla Model Y Perf.LR AWD 21" & $\$ 60,990$ & $\$ 1,200$ & & \\
\hline
\end{tabular}

\section{FUTURE ANALYSIS}

Tesla electric is being considered the transportation of the future. Considering the company's performance in the last four years, it has been registering a significant income loss. In 2017, Tesla registered a loss of $\$ 1.92$ billion. However, in 2020, the company registered a positive net income of $\$ 0.86$ billion. The company revenue has also been growing from 2017 to 2020. For example, Tesla's revenue was $\$ 11.75$ billion in 2017 and this increased to $\$ 31.53$ billion in the 2020 financial year. This is a positive trend for the company. Its share price has also been growing indicating that more investors are confident with Tesla. For example, in December 2018, the company shares were costing $\$ 61.71$ per share. However, this improved, and by February 2020, the company's share price was $\$ 161.68$.

\subsection{Financial analysis}

Electric cars have become the alternative mode of transportation in the future. This has placed Tesla Company in a better position to increase its market share as well as improve its profitability level. In an article by Lizzy Gurdus (2021), the market has already decided the winner of electric vehicles to be the Tesla Company [11]. As a result, the company is projected to generate more revenue in the future as the demand for electric cars increases. The future success of Tesla, therefore, lies in the fact that the carbon dioxide level has become a serious concern to many and this has made consumers look for an alternative to prevent climate change. As a result, consumers in near future will purchase more electric cars

Tesla's future analysis can be determined by looking at the company's past performance. In the 2017 financial year, the company revenue was $\$ 11.75$ billion. This increased to $\$ 21.46$ billion in 2018 and further to $\$ 31.53$ billion in the 2020 financial year. This is a positive trend that indicates how Tesla has been able to increase its revenue levels for the past four years. This also indicates that the company will be able to increase its revenue in the future as demand for electric cars increases.

The company's profitability is a true reflection of the future progress of Tesla Company. For example, the company's gross profit has improved from the 2017 financial year to the year ending 2020. In 2017, the gross profit generated by the company was $\$ 2.22$ billion. This improved to $\$ 6.63$ billion by the year ending 2020 . The company's net income has also been growing since 2017. In 2017, Tesla registered a loss of $\$ 1.92$ billion. In 2018, the company also registered a loss of $\$ 1.06$ billion. The loss in income also decreased in 2019 to $\$ 0.78$ billion. However, in 2020 , the company registered a positive net income of $\$ 0.86$ billion. This trend shows that Tesla is having a brighter future especially as the demand for electric cars increases (Figure 2). 


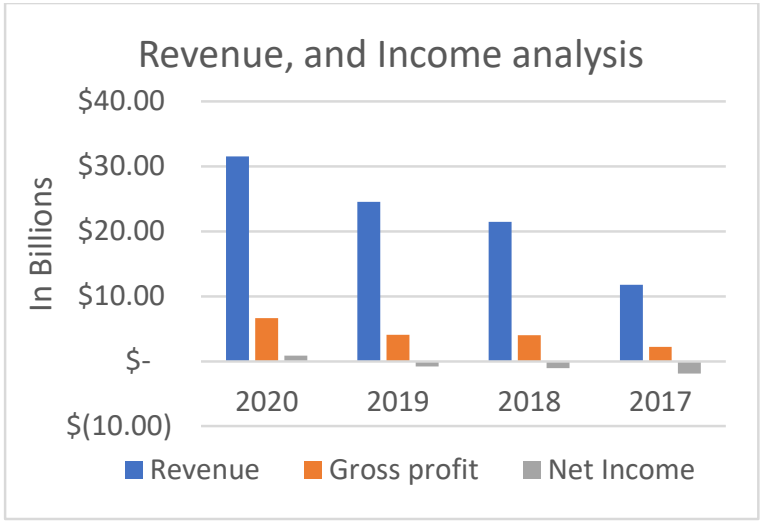

Figure 2. Tesla's revenue and income analysis.

Tesla's share price as shown by Figure 3 has significantly improved for the past few years. For example, in December 2018, the company shares were costing \$61.71 per share. However, this improved, and by February 2020, the company's share price was $\$ 161.68$. This shows the company shares have a positive trend and more investors are optimistic about the company's future growth [11]. By January 2021, the company shares were $\$ 874.82$. Although there is a downward trend since January 2021 in terms of share price, the company's significant growth in share price for the last 2 years is a positive indication that many investors are confident of the company's future growth. This growth is attributed to the future demand for electric cars as more consumers become environmentally conscious.

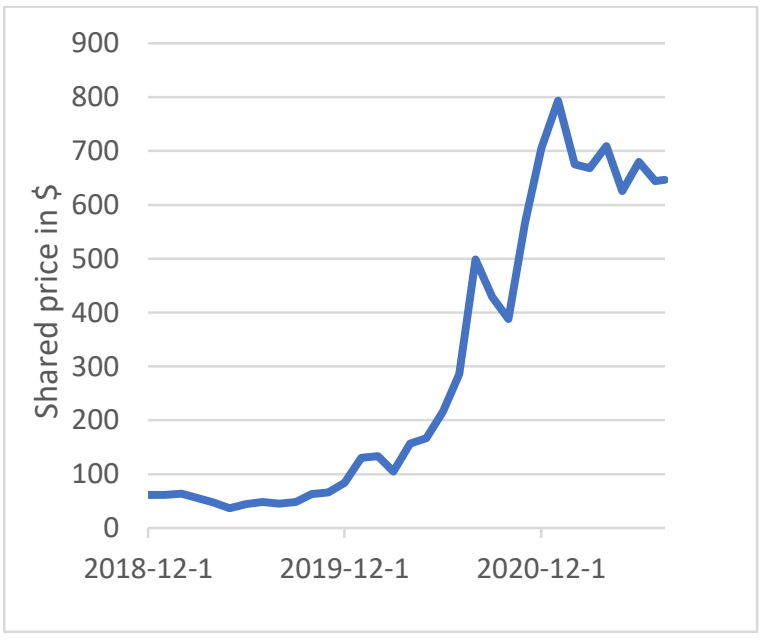

Figure 3. The share price for Tesla from 2018 to 2021.

\subsection{Competitor analysis}

The issue of competition has become common among most companies, with each company trying to come up with strategies that will make it stand out in the available markets [12]. The same case applies to Tesla where the company has been having major competitors. One of these competitors includes the Ford Motor Company [13]. Despite, the fact that Ford is known to be a traditional motor vehicle company, the fact remains that the company has also developed the need to join the electric car market as a way of moving in line with the changing consumer preferences. Within the electric-powered motor space, Ford Motor Company has continued to pose major threats to the future success of Tesla [13]. This is mainly attributed to the fact that Ford is attracting high numbers of new customers. At the same time, more customers have continued to demonstrate their concerns about the high prices, size, and even the driving experience they get from Tesla SUVs. These concerns have therefore made these customers prefer Ford Motor Company SUVs over Tesla Motors.

There is also The Volkswagen Group, which is a German-based automotive manufacturing company. Also being a traditional company, Volkswagen has also ventured into the electric car motor space and has vowed to ensure that it has also dominated the growing market of electric vehicles. To achieve this goal, the company is projecting to have manufactured approximately 1.5 million electric vehicles by the year 2025 . This is to tap the growing market of electric cars and ensure that it has dealt with the issue of competition [13]. With this, it is clear that the traditional, as well as other upcoming companies and their new pace of tapping the electric car market, remain the major challengers of Tesla's efforts to increase its market share.

\section{RECOMMENDATIONS}

The current circumstance is that Tesla still faces problems but meanwhile the breakthroughs. As a pure electric vehicle company based on innovation, Tesla can do more than it has achieved today. Therefore, the improvement of Tesla in the long term is advised below in the area of product sensitivity and public automation.

\subsection{Gain entrance to other industries}

Tesla is recommended to gain entrance to other industries by pursuing product placements such as in video games, toys, and other forms of entertainment. This helps improve the reach of Tesla by increasing consumer awareness of the brand. In the toy industry, for example, the statistics in Figure 4 show that from 2015 to 2020, the average annual growth rate was $18.5 \%$. Additionally, the market size of the global toy industry in 2020 was as high as $\$ 23.7$ billion. It is also predicted that the global toy industry will expand further in the next few years. Therefore, Tesla can use the way of making Tesla toy models improve brand sensitivity among children, who are also potential customers, to further broaden the channels of future clients. If divisions for the different promising industries have been set up, the company could possess a wider range of revenue sources and likewise diversification of risk. 


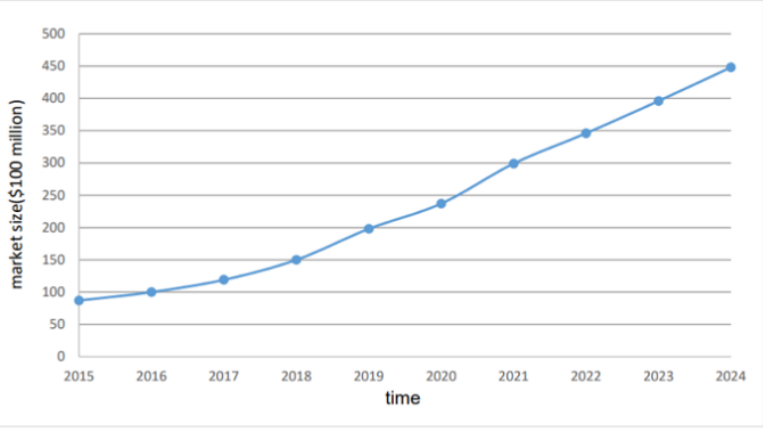

Figure 4. The market size of the toy industry.

\subsection{Develop autonomous public transportation}

Some studies have shown that in certain areas, adolescents, namely Generation Z, are less likely to learn a driver's license or own a private car compared to other generations [14]. With private car ownership experiencing a decline amongst youngsters, it is recommended that Tesla put more emphasis into research and development of automation and vehicles used in common, which would render the company opportunities to shift production more readily from private vehicles to other forms of commercial autonomous public transportation such as electric taxis and car-sharing. For instance, Tesla can establish an electric car-sharing service (ECS). Under the behavioral intention of accepting ECS dominated importantly by social influence [15], Tesla can achieve an advanced breakthrough of the service by a certain social reputation accumulated today.

\section{CONCLUSION}

In today's world background, with the increasing environmental pollution and the increasing shortage of fossil fuels, countries around the world pay more attention to environmental protection, new energy technology research and development, and energy security. The fossil energy internal combustion engine, represented by oil, is gradually replaced by the power system of other energy sources in the field of highway transportation, this also brings a good opportunity for the development of the new energy vehicle industry with electrification as the core technology.

As the global and the consumers' preferences in automobiles continue to change, the topic of focus was 'Transportation of the Future, where the major focus was on Tesla Motors. Being an American-based automobile company, Tesla has mainly invested in electric cars as a way of promoting sustainability. Due to the high-quality automobiles that the company has continued to offer its customers, its performance within the electric cars markets has been commendable. This is because the company is currently known to be leading in these markets in terms of market share. The company income changed from a loss in 2017 to a profit in 2020 . This is also shown by an increase in their price share. As research has indicated, however, the market share of Tesla Motors is likely to decline in the future. This will be a result of increased competition and a decline in the level of demand for electric cars, especially among the upcoming generations. The recommendation to Tesla Company in the future is to intensify and invest more in the research and development of electric cars. This is because this is the ideal car for the future generation. The second recommendation is for Tesla to increase its marketing and promotion campaign. This is to be able to increase its market penetration and become the best company to purchase electric cars, especially by the young generation.

However, this paper lacks investigation and research in the management and monitoring of the quality of Tesla cars. In recent years, the quality problems of Tesla have repeatedly appeared and caused widespread concern in society. Therefore, it is of great importance to implement a detailed investigation of the quality of the product. The safety problem cannot be ignored. Moreover, the study of Tesla in some regions in this paper is still incomplete. Tesla faces different market influence factors in many different countries and regions, so the company will adopt special local strategies. In the future research, the quality assessment will be included in an important part of market research, and Tesla strategy analysis, future trends, and suggestions for each region will be discussed respectively after obtaining authoritative and reliable social data.

\section{REFERENCES}

[1] Martins Lívia Salles, Guimarães Lucas Fonseca, Botelho Junior Amilton Barbosa, Tenório Jorge Alberto Soares \& Espinosa Denise Crocce Romano. (2021). Electric car battery: An overview on global demand, recycling and future approaches towards sustainability. Journal of Environmental Management(\{4\}),doi:10.1016/J.JENVMAN.2021. 113091.

[2] Fevang Elisabeth,Figenbaum Erik,Fridstrøm Lasse,Halse Askill H.,Hauge Karen E.,Johansen Bjørn G. \& Raaum Oddbjørn.(2021).Who goes electric? The anatomy of electric car ownership in Norway. Transportation Research Part D( $\{4\})$, doi:10.1016/J.TRD.2021.102727.

[3] Nor Azila Mohd Noor \& Mohd Norsam Mohd Sari. (2020). Consumption Values and Consumers' Attitude towards Intention to Purchase Electric Car. Journal of Critical Reviews(15), doi:10.31838/JCR.07.15.112.

[4] Sommer Stephan \& Vance Colin. (2021). Do more chargers mean more electric cars?. Environmental 
Research Letters(6), doi:10.1088/17489326/AC05F0.

[5] Zoe Long, Jonn Axsen, Inger Miller \& Christine Kormos. (2019). What does Tesla mean to car buyers? Exploring the role of automotive brand in perceptions of battery electric vehicles. Transportation Research Part A( $\{4\})$, doi:10.1016/j.tra.2019.08.006.

[6] RAYMOND EYO EYO.(2019). Tesla's Business Model in China's Electronic Vehicle Market and Its Influence (Master's Thesis, Shandong University of Finance and Economics).https://kns.cnki.net/KCMS/detail/detai 1.aspx ?dbname $=$ CMFD202002 $\&$ filename $=101913$ 8678.nh

[7] Jian-hua Liu \& Zhan Meng.(2017).Innovation Model Analysis of New Energy Vehicles: Taking Toyota, Tesla and BYD as an Example. Procedia Engineering $(\{4\})$, doi:10.1016/j.proeng.2017.01.248.

[8] V.J. Thomas \& Elicia Maine.(2019).Market entry strategies for electric vehicle start-ups in the automotive industry - Lessons from Tesla Motors. Journal of Cleaner Production( $\{4\})$, doi:10.1016/j.jclepro.2019.06.284.

[9] Chen, Y., Chowdhury, S. D., \& Donada, C. (2019). Mirroring hypothesis and integrality: evidence from tesla motors. Journal of Engineering and Technology Management, 54, 41-55.

[10] Park Namgyoo Kenny, Chun Young Shin \& Jang Wanjin.(2019).Tesla Challenges 100 Years of Automotive Industry History. Korea Business Review(3),doi:(https://www.dbpia.co.kr/journal/art icleDetail?nodeId=NODE08765805\&language $=$ ko _KR\#)

[11] Gurdus, L. (2021). Market has already decided the winner of the electric vehicle race, trader says. Retrieved from https://www.cnbc.com/2021/06/29/tesla-tradersays-market-has-decided-winner-of-electricvehicle-race.html.

[12] Hancock, P. A., Nourbakhsh, I., \& Stewart, J. (2019). On the future of transportation in an era of automated and autonomous vehicles. Proceedings of the National Academy of Sciences of the United States of America, 116(16), 7684-7691. https://doi.org/10.1073/pnas.1805770115

[13] Elliott, R. (2021). Tesla Faces New Reality of Tough Competition. WSJ. Retrieved 8 July 2021, from https://www.wsj.com/articles/tesla-faces-newreality-of-tough-competition-11615478406.
[14] Chatterjee, K., Goodwin, P., Schwanen, T., Clark, B., Jain, J., Melia, S., Middleton, J., Plyushteva, A., Ricci, M., Santos, G. and Stokes, G.: Young People's travel—what's changed and why? Review and analysis. Report to Department for Transport. UWE Bristol, UK (2018). www.gov.uk/government/publications/ youngpeoples-travel-whats-changed-andwhy

[15] Curtale, R., Liao, F., \& van der Waerden, P. (2021). User acceptance of electric car-sharing services: The case of the Netherlands. Transportation Research Part A: Policy and Practice, 149, 266-282. 